Article

\title{
Phytochemistry of Three Ecuadorian Lamiaceae: Lepechinia heteromorpha (Briq.) Epling, Lepechinia radula (Benth.) Epling and Lepechinia paniculata (Kunth) Epling
}

\author{
Gianluca Gilardoni ${ }^{1, *}{ }^{\mathbb{D}}$, Jorge Ramírez ${ }^{1}{ }^{\mathbb{D}}$, Mayra Montalván ${ }^{1}$, Willan Quinche ${ }^{1}$, \\ Jackeline León ${ }^{1}$, Lita Benítez ${ }^{1}$, Vladimir Morocho ${ }^{1} \mathbb{D}$, Nixon Cumbicus ${ }^{1}$ and Carlo Bicchi ${ }^{2}$ \\ 1 Departamento de Química y Ciencias Exactas, Universidad Técnica Particular de Loja (UTPL), Calle M. \\ Champagnat s/n, 1101608 Loja, Ecuador; jyramirez@utpl.edu.ec (J.R.); mayste_95@hotmail.com (M.M.); \\ wstalin.14@gmail.com (W.Q.); jackileo@hotmail.es (J.L.); lsbenitez1@utpl.edu.ec (L.B.); \\ svmorocho@utpl.edu.ec (V.M.); nlcumbicus@utpl.edu.ec (N.C.) \\ 2 Dipartimento di Scienza e Tecnologia del Farmaco, Università degli Studi di Torino, Via P. Giuria 9, \\ 10125 Torino, Italy; carlo.bicchi@unito.it \\ * Correspondence: gianluca.gilardoni@gmail.com; Tel.: +593-990902426
}

Received: 27 November 2018; Accepted: 15 December 2018; Published: 20 December 2018

\begin{abstract}
In this research, the leaves of Lepechinia heteromorpha (Briq.) Epling, Lepechinia radula (Benth.) Epling and Lepechinia paniculata (Kunth) Epling have been collected in order to perform a phytochemical study. The first species was distilled to obtain a novel essential oil (EO), while the others were submitted to ethyl acetate extraction and secondary metabolite isolation. The chemical composition of the EO from L. heteromorpha has been investigated by Gas Chromatography-Mass Spectrometry (GC-MS) and Gas Chromatography with Retention Indices (GC(RI)), identifying 25 constituents. A major compound, (-)-ledol (21.2\%), and a minor compound, (-)-caryophyllene oxide $(1.0 \%)$, were isolated from the EO and their structures confirmed by Nuclear Magnetic Resonance (NMR) spectroscopy. Other major constituents of the EO were viridiflorene $(27.3 \%)$, $(E, E)$ - $\alpha$-farnesene $(1.4 \%)$, spirolepechinene and $(E)$ - $\beta$-caryophyllene $(7.1 \%$ each), allo-aromadendrene (6.1\%), camphor $(1.7 \%)$, limonene $(1.3 \%)$ and $\beta$-phellandrene $(4.6 \%)$. The enantiomeric composition of the EO monoterpene fraction was also studied, determining the enantiomeric excess and distribution of $\alpha$-pinene, limonene, $\beta$-phellandrene and camphor. The ethyl acetate extract of $L$. radula and L. paniculata were fractionated by column chromatography. Spathulenol, angustanoic acid E and 5-hydroxy-4',7-dimethoxy flavone were isolated from L. radula extract; ledol, guaiol and (-)-carnosol were found in L. paniculata.
\end{abstract}

Keywords: Ecuador; Lamiaceae; essential oil; ledol; caryophyllene oxide; spathulenol; angustanoic acid E; 5-hydroxy-4',7-dimethoxy flavone; guaiol; carnosol

\section{Introduction}

Ecuador is one of the seventeen mega-biodiverse countries in the world [1]. Therefore, it is a great source of new natural products, since most of the botanical species have never been studied before for their secondary metabolites [2]. Furthermore, Ecuador hosts many indigenous cultures, maintaining an ancestral knowledge that includes traditional medicine. In recent years, this cultural heritage has often been investigated to select interesting botanical targets, in particular to find new biologically active compounds. The secondary metabolites can be classified as volatile or non-volatile. If the volatile fraction is isolated by steam distillation, it is an essential oil (EO). From a qualitative point of view, EOs 
are often mixtures of known compounds; however, their quantitative composition can be very different from species to species. The quali-quantitative composition of an $\mathrm{EO}$ is responsible for its sensorial and biological properties. Furthermore, several components in an EO are chiral compounds and they are often present as pure enantiomers or in an enantiomeric excess and, seldom, in racemic form [3]. Since the enantiomers of a chiral compound may have different biological and sensorial properties [4], the recognition of chiral compounds by enantioselective GC is a useful but seldom applied step in the chemical study of a plant EO fraction [5].

Our interest in the genus Lepechinia is due to the abundance of EOs and the variety of secondary metabolites produced [6-12]; it is not based on an ethnomedical evidence, traditional use or biological activity. Therefore, this study can be considered as a contribution to the phytochemistry of genus Lepechinia, reporting the first chemical description of the EO distilled from Lepechinia heteromorpha (Briq.) Epling. Concerning Lepechinia radula (Benth.) Epling and Lepechinia paniculata (Kunth) Epling, two previous studies, describing the respective EOs, are now complemented with the purification and characterization of some major secondary metabolites, obtained by ethyl acetate extraction.

L. heteromorpha is botanically described with the accepted name Sphacele conferta Benth and with the synonym Sphacele heteromorpha Briq. [13]. It is a shrub native of the Andean region, growing wild between 2000 and $3000 \mathrm{~m}$ above the sea level. The species is distributed in Ecuador, where it has been found in the provinces of Azuay, Cañar and Loja [14]. To the best of the authors' knowledge, no chemical or bio-activity studies about this plant have been reported in literature until now.

L. radula is also a shrub, native of the Andean region and growing between 2000 and $2500 \mathrm{~m}$ above sea level. This plant is described with the accepted name Sphacele radula Benth. [15] and three botanical synonyms are known: Alguelagum cordifolium (Benth.) Kuntze, Alguelagum radula (Benth.) Kuntze and Sphacele cordifolia Benth [16]. The plant has been described in Ecuador in the provinces of Azuay and Loja [17]. An EO composition of this species has already been reported in the literature [18].

L. paniculata is an endemic shrub, growing wild between 2000 and $2500 \mathrm{~m}$ above sea level. It has been described in the Ecuadorian provinces of Azuay and Loja. Synonyms of this species are: Alguelagum paniculatum (Kunth.) Kuntze, Sideritis paniculata Kunth, and Sphacele paniculata (Kunth) Benth. [19]. According to some literature, an accepted name is Lepechinia betonicifolia (Lam.) Epling [20], although other sources consider it as a different species [14]. An EO of this plant has already been studied [21].

To the best of the authors' knowledge, nothing is reported in the literature about secondary metabolites from organic solvent extracts of L. radula and L. paniculata.

Concerning the traditional use of these plants, only L. paniculata is known with a specific name and ethnomedical use. According to the literature [22], this species is called llanllun or azul yallun by the Kichwa people of the Ecuadorian Andean region, who use it in both supernatural and physical applications. The buds are tied at the forehead for treating the "mal de aire", a sort of evil eye. The same application is considered effective against headache, while flower infusions are used to treat nervous diseases. However, two different terms seem to be used to indicate generically that the species belongs to the whole genus Lepechinia: zhalshon negro grande in Spanish and yana zhalshon in Kichwa [23]. Among the indigenous people Saraguro, settled in the province of Loja, the leave are used to treat "mal de aire" and aches in muscles and bones, simply binding them to the aching area.

\section{Results}

\subsection{EO from L. Heteromorpha Leaves}

\subsubsection{Chemical Analysis}

The EO distilled from leaves of L. heteromorpha was a yellowish waxy solid, easily melted at low temperatures. Due to its physical state, it was recovered dissolving it in dichloromethane and the yield of each distillation was determined through semi-quantitative Gas Chromatographic analysis with Flame Ionization Detector (GC-FID). The resulting average yield was $0.06 \pm 0.029 \%(w / w)$, referred 
to fresh plant material. The detected and quantified components cover $99.1 \%$ of the EO; its specific rotatory power was $[\alpha]_{D}^{20}=-5.6\left(\mathrm{c} 5.07\right.$ in $\mathrm{CH}_{2} \mathrm{Cl}_{2}$ ). The qualitative and semi-quantitative compositions of the $\mathrm{EO}$ are reported in Table 1.

Table 1. Chemical analysis of L. heteromorpha essential oil (EO) on a DB-5ms column.

\begin{tabular}{|c|c|c|c|c|}
\hline Reference LRIs & Calculated LRIs & Compounds & $\% 1$ & $\sigma$ \\
\hline 932 & 931 & $\alpha$-Pinene & 1.2 & 0.71 \\
\hline 946 & 946 & Camphene & 2.4 & 0.45 \\
\hline 969 & 976 & $\beta$-Pinene & 0.4 & 0.18 \\
\hline 988 & 988 & Myrcene & 0.4 & 0.22 \\
\hline 1003 & 1003 & Mentha-1(7),8-diene & 0.4 & 0.23 \\
\hline 1007 & 1005 & iso-Sylvestrene & 0.2 & 0.13 \\
\hline 1020 & 1015 & $p$-Cymene & 0.5 & 0.26 \\
\hline 1022 & 1017 & $o$-Cymene & 1.0 & 0.01 \\
\hline 1024 & 1029 & Limonene & 1.3 & 0.41 \\
\hline 1025 & 1029 & $\beta$-Phellandrene & 4.6 & 1.02 \\
\hline 1141 & 1145 & Camphor & 1.7 & 0.46 \\
\hline 1400 & 1404 & Sibirene & 3.2 & 0.32 \\
\hline 1417 & 1411 & $(E)$ - $\beta$-Caryophyllene & 7.1 & 0.77 \\
\hline 1439 & 1439 & Aromadendrene & 1.0 & 0.18 \\
\hline 1449 & 1445 & Spirolepechinene & 7.1 & 0.93 \\
\hline 1458 & 1451 & allo-Aromadendrene & 6.1 & 1.00 \\
\hline 1452 & 1453 & $\alpha$-Humulene & 1.2 & 0.19 \\
\hline 1496 & 1484 & Valencene & 1.6 & 0.23 \\
\hline- & 1487 & Undetermined (MW 204) & 3.7 & 1.84 \\
\hline 1492 & 1489 & cis- $\beta$-Guaiene & 0.3 & 0.16 \\
\hline 1496 & 1497 & Viridiflorene & 27.3 & 1.80 \\
\hline 1505 & 1503 & $(E, E)-\alpha$-Farnesene & 1.4 & 0.41 \\
\hline- & 1509 & Undetermined (MW 204) & 0.2 & 0.12 \\
\hline 1511 & 1516 & $\delta$-Amorphene & 1.0 & 0.98 \\
\hline 1559 & 1549 & Germacrene B & 1.6 & 0.83 \\
\hline $1592^{2}$ & 1593 & Caryophyllene oxide & 1.0 & 0.59 \\
\hline 1602 & 1601 & $(-)$-Ledol ${ }^{3}$ & 21.2 & 4.32 \\
\hline \multicolumn{3}{|c|}{ Monoterpene hydrocarbons } & 12.4 & \\
\hline \multicolumn{3}{|c|}{ Oxygenated monoterpenes } & 1.7 & \\
\hline \multicolumn{3}{|c|}{ Sesquiterpene hydrocarbons } & 62.8 & \\
\hline \multicolumn{3}{|c|}{ Oxygenated sesquiterpenes } & 22.2 & \\
\hline \multicolumn{3}{|c|}{ Others } & - & \\
\hline \multicolumn{3}{|c|}{ Total identified } & 99.1 & \\
\hline
\end{tabular}

The sesquiterpene fraction of an EO is often very complex and the characterization of single components through preparative isolation and spectroscopic elucidation is usually recommended. The common way is by preparative column chromatography, on normal or reversed phase, followed by NMR and MS experiments. The main problem in achieving this result is the very similar polarity of the isomeric terpenes, which usually does not permit an efficient preparative separation. In the case of our EO, only ledol and caryophyllene oxide could be separated and purified by liquid chromatography, due to the different relative polarity.

\subsubsection{Enantioselective GC Analysis}

The recognition of chiral components in the EO was carried out with an enantioselective GC column, coated with 2,3-diacethyl-6-tert-butylsilyl- $\beta$-cyclodextrin as chiral selector. The enantiomers of $\alpha$-pinene, $\beta$-phellandrene and the enantiomerically pure $(R)$-limonene and $(R)$-camphor were recognized. Additionally, allo-aromadendrene was probably present in two enantiomeric forms, however, its configuration was not attributed because of the lack of the reference standard of at 
least one enantiomer. The percentage enantiomeric distribution and enantiomeric excess (ee) of the identified enantiomers are shown in Table 2. Figure 1 reports the enantioselective GC pattern of L. heteromorpha EO.

Table 2. Enantioselective analysis of $L$. heteromorpha EO on diacethyl terbutylsilyl- $\beta$-cyclodextrin column.

\begin{tabular}{cccc}
\hline LRIs & Enantiomers & Enantiomeric Distribution (\%) & ee (\%) \\
\hline 917 & $(S)$ - $\alpha$-pinene & 8.7 & \multirow{2}{*}{82.6} \\
926 & $(R)$ - $\alpha$-pinene & 91.3 & 100.0 \\
\hline 1054 & $(R)$-limonene & 100.0 & 76.6 \\
\hline 1072 & $(+)-\beta$-phellandrene & 88.3 & 100.0 \\
1091 & $(-)$-phellandrene & 11.7 & \\
\hline 1262 & $(R)$-camphor & 100.0 &
\end{tabular}

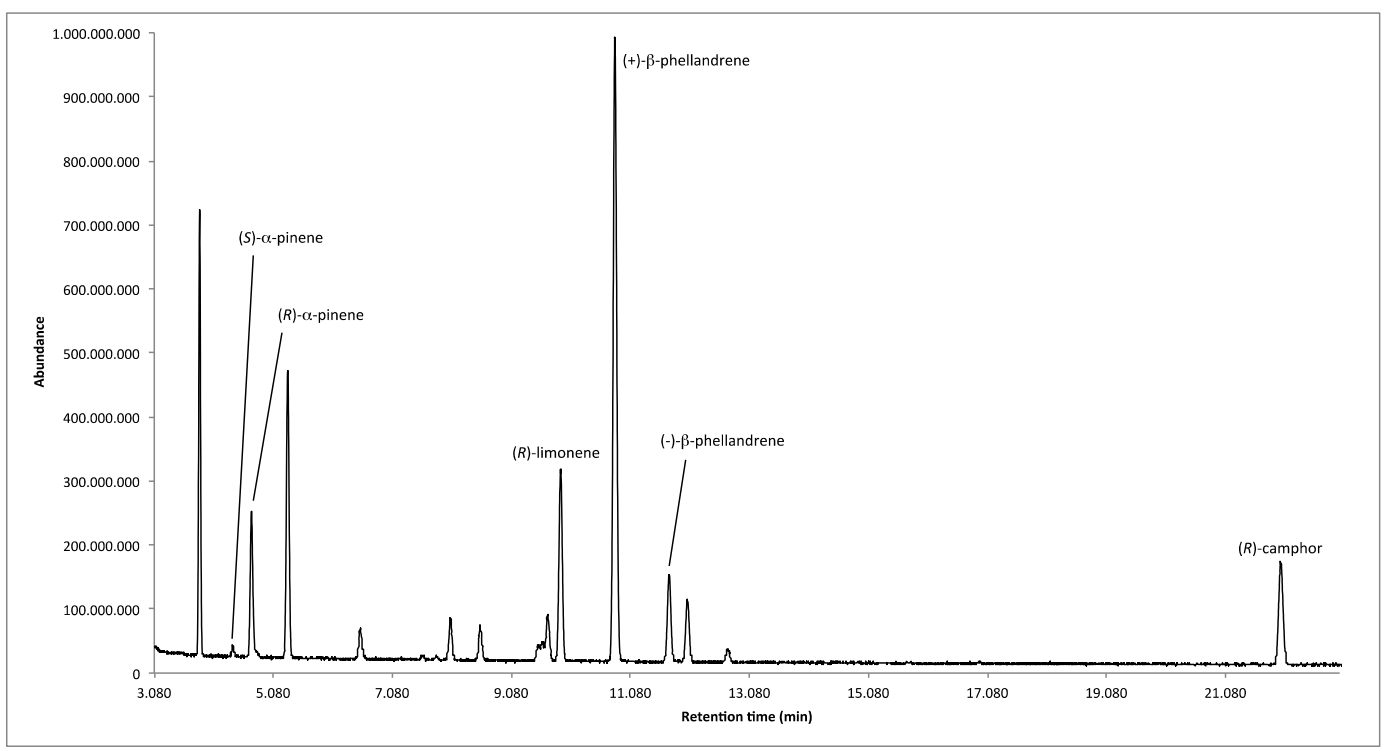

Figure 1. Enantioselective GC pattern of L. heteromorpha EO on diacethyl terbutylsilyl- $\beta$-cyclodextrin capillary column.

\subsubsection{Characterization of (-)-Ledol (1)}

(-)-Ledol (1) is the only sesquiterpene alcohol present in this EO, counting for more than $21 \%$ of the total analysis. Its molecular structure is shown in Supplementary Material. In order to set up the preparative purification method, four fractions of increasing polarity were previously obtained by normal phase preparative thin layer chromatography (TLC), indicated with numbers from 1 to 4 . These fractions were analysed under the same conditions as those adopted for the GC-MS analysis of the total oil. From the GC-MS patterns of the resulting fractions, it can be observed that fraction 3 mainly consists of (-)-ledol (see Supplementary Material).

After column chromatography (CC) fractionation, a sample of (-)-ledol was obtained, whose molecular structure was confirmed by ${ }^{1} \mathrm{H}$ and ${ }^{13} \mathrm{C} \mathrm{NMR}$. The resulting spectroscopic data were identical to those reported in the literature. Also the specific rotatory power was consistent with the value of literature for (-)-ledol [25]. According to ${ }^{1} \mathrm{H}$ NMR, the purity of compound (1) can be estimated of about $95 \%$.

\subsubsection{Characterization of (-)-Caryophyllene Oxide (2)}

During the purification process of compound (1), a second minor sesquiterpene was obtained as a by-product, and it was identified as caryophyllene oxide (2) by ${ }^{1} \mathrm{H}$ and ${ }^{13} \mathrm{C}$ NMR experiments [26]. 
Its amount and purity were not sufficient to measure reliably the specific rotatory power; however, it showed to be levorotatory. According to ${ }^{1} \mathrm{H}$ NMR, the purity of compound (2) can be estimated of about $85 \%$.

\subsection{Ethyl Acetate Extract of Lepechinia Radula}

The ethyl acetate extract of $L$. radula was investigated for secondary metabolites purification and characterization.

\subsubsection{Identification of Spathulenol (3)}

Spathulenol (3) is a quite common sesquiterpene alcohol, obtained by normal phase fractionation of the ethyl acetate extract. The resulting white solid was identified as spathulenol by ${ }^{1} \mathrm{H}$ NMR, electron impact mass spectrometry (EIMS), and GC(RI). LRI is referred to the homologous series of $n$-alkanes on a DB-5 column (LRI = 1583). All spectroscopic and gas chromatographic data were in agreement with those reported in the literature $[27,28]$. Neither ${ }^{13} \mathrm{C}$ NMR nor specific rotatory power experiments were run because of the small amount obtained.

\subsubsection{Identification of Angustanoic Acid E (4)}

Angustanoic acid E (4) was obtained as a crystalline compound by normal phase column chromatography, eluting with a mixture of hexane/ethyl acetate. Its purity was controlled by normal phase TLC, with hexane/ethyl acetate 90:10 as eluting phase (Rf: 0.71). The structure was elucidated by ${ }^{1} \mathrm{H},{ }^{13} \mathrm{C}$ and DEPT NMR experiments. All spectroscopic data were consistent with those reported in the literature [29].

\subsubsection{Identification of 5-hydroxy-4',7-dimethoxy flavone (5)}

A yellowish crystalline compound was isolated and identified as 5-hydroxy-4',7-dimethoxy flavone (5) by ${ }^{1} \mathrm{H}$ and ${ }^{13} \mathrm{C}$ NMR experiments; the results were in perfect agreement with those reported in the literature [28]. Its purity was controlled by normal phase TLC with hexane/ethyl acetate 90:10 as eluting phase (Rf: 0.67).

\subsection{Ethyl Acetate Extract of Lepechinia paniculata}

The ethyl acetate extract of L. paniculata was studied for secondary metabolites purification and characterization.

\subsubsection{Identification of Ledol (3) and Guaiol (6)}

Ledol (3) was identified in a fraction eluted with hexane/ethyl acetate 90:10, also containing guaiol (6). The fraction was analysed by GC(RI), where the two sesquiterpenoids were separated and identified by comparison of their LRIs and EIMS spectra to those of the literature [27] and to the reference sample isolated from the EO of L. heteromorpha.

\subsubsection{Characterization of (-)-Carnosol (7)}

Carnosol was isolated from a more polar fraction (hexane/ethyl acetate about 80:20) as white crystals. The sample was submitted to ${ }^{1} \mathrm{H}$ NMR providing spectral data identical to those obtained from a reference sample, isolated and characterized by X-ray diffraction from L. mutica [6].

\section{Discussion}

\subsection{EO of L. Heteromorpha}

In the EO of L. heteromorpha, 25 constituents were identified and quantified. Major components were viridiflorene (27.3\%), (E,E)- $\alpha$-farnesene $(1.4 \%)$, ledol $(21.2 \%)$, spirolepechinene 
and (E)- $\beta$-caryophyllene (7.1\% each), allo-aromadendrene (6.1\%), camphor (1.7\%), limonene $(1.3 \%)$ and $\beta$-phellandrene (4.6\%). Sesquiterpenoids were the main fraction of the EO, accounting for about $85 \%$ of the whole sample. In particular, (-)-ledol is the only sesquiterpene alcohol in the EO. Its abundance (21.2\%) makes this EO a good source of this compound in a seemingly pure enantiomeric form, easy to isolate by normal phase liquid chromatography. Enantioselective GC showed that only $\alpha$-pinene and $\beta$-phellandrene were present with an enantiomeric excess, the others monoterpenes seemed to present as pure enantiomers. However, with the exception of $(R)$-camphor and $(R)$-limonene, it was not possible to attribute the absolute configuration to others enantiomers because of the unavailability of reference standards. Concerning caryophyllene oxide, it has sometimes been considered an artefact, produced by spontaneous oxidation and indicating the aging of the EO. However, in this case, we are inclined to consider it as an original component, as the fraction was properly stored and analysed soon after distillation.

In a previous work [7], some of the authors compared the major constituents of the EOs obtained from many Lepechinia spp. From this comparison, a common qualitative and quantitative profile did not emerge and an almost equal contribution from monoterpenes and sesquiterpenes was observed. The most common constituent was $\delta$-3-carene, present in seven of 14 species, followed by $(E)-\beta$-caryophyllene that was observed in five. In this respect, L. heteromorpha EO did not contain $\delta$-3-carene but showed the presence of abundant $(E)$ - $\beta$-caryophyllene (about $7.1 \%$ ). Other major constituents, described at least in two species, were borneol, $\beta$-phellandrene, 1,8-cineole, camphor, ledol, $\alpha$-pinene and $\beta$-pinene. Except for borneol, 1,8-cineole and camphor, all the other compounds were detected in L. heteromorpha. A more accurate comparison was performed between the EOs from flowers and leaves of L. mutica, where important quantitative differences were observed [6]. In fact, while monoterpene fraction was prevalent in flowers (about $55.5 \%$ of the whole EO), sesquiterpenes were dominant in leaves (63.2\%). However, in both cases a sesquiterpene alcohol was the relative major constituent, being eudesm-7(11)-en-4-ol the most abundant in flowers (13.0\%) and shyobunol in leaves $(10.8 \%)$. The situation was quite different for L. heteromorpha, where most of the compounds detected in L. mutica were absent. In fact, although its EO was mainly composed of sesquiterpenes $(85.0 \%)$, it presented only a total of 26 detected metabolites, against about 80 compounds in L. mutica flowers and leaves.

\subsection{Ethyl Acetate Extract of L. Radula and L. Paniculata}

As for the EO of L. heteromorpha, the ethyl acetate extracts of L. radula and L. paniculata also contained compounds typical of this genus, i.e., 5-hydroxy-4',7-dimethoxy flavone (5), (-)-carnosol (7), both described in L. mutica [6], and ledol (1), isolated from the EO of L. heteromorpha. Ledol and guaiol are diastereoisomers of viridiflorol, a sesquiterpene alcohol also present in L. mutica [6]. However, the most interesting component is probably (-)-carnosol, i.e., a well-known diterpenoid characterized by a variety of biological activities [30-35]. In particular, it is important for its antioxidant properties in rosemary (Rosmarinus officinalis) [36] and for a remarkable activity as butyrylcholinesterase (BChE) inhibitor in L. mutica [37].

Concerning (-)-spathulenol, it has been described sometimes to be an artefact, deriving from (-)-bicyclogermacrene. Asakawa et al. showed that the fresh extracts of Dicranolejeunea yoshinagana and others liverworts contained (-)-bicyclogermacrene, which completely disappeared after some months, with a contemporary increase of the amount of (-)-spathulenol. The same conversion took place in four days with pure (-)-bicyclogermacrene [38].

Sesquiterpenes, diterpenes and flavonoids, closely related to those observed in the ethyl acetate extracts of L. radula and L. paniculata, were also identified in other Lepechinia spp., together with pentacyclic triterpenes and other metabolites. L. speciosa [39], L. caulescens [40,41], L. meyeni [42], L. hastata [42], L. chamaedryoides [43], L. bullata [12,44] and L. graveolens [8] were particularly relevant for the presence of daucane sesquiterpenes and abietanic diterpenes. In particular, terpenes such as spathulenol, carnosic acid, carnosol and spirolepechinene, or flavonoids such as pinocembrin, 
5-hydroxy-4',7-dimethoxyflavone and luteolin-7-O-glucuronide were obtained and purified from these species.

\section{Materials and Methods}

\subsection{General Information}

The GC(RI) analyses were carried out with an Agilent Technology (Wilmington, DE, USA) 6890N gas chromatograph, coupled to an Agilent Technology single quadrupole mass spectrometer, series 5973 INERT. The ion source was an Electron Impact (EIMS) at $70 \mathrm{eV}$. Samples were injected with an automatic split/splitless injector, series 7683 . The instrument was equipped with a DB-5MS (5\% phenyl-methylpolysiloxane) Agilent $122-5532$ capillary column $(30 \mathrm{~m} \times 0.25 \mathrm{~mm} \times 0.25 \mu \mathrm{m}$ of film thickness).

Semi-quantitative GC analyses were performed with the same GC-MS system, equipped with a flame ionization detector (FID) under the same analytical conditions.

The enantioselective GC analysis was carried out with an enantioselective capillary column, based on $30 \%$ diacethylterbutylsilyl- $\beta$-cyclodextrin in PS-086 $(25 \mathrm{~m} \times 0.25 \mathrm{~mm} \times 0.25 \mu \mathrm{m}$, purchased from MEGA, Milan, Italy), installed in the same GC-MS system. Helium was used as carrier gas (Indura, Guayaquil, Ecuador).

For preparative column chromatography (CC), silica gel 60, particle size $0.063-0.200 \mathrm{~mm}$ (Merck KGaA, Darmstadt, Germany), was used as stationary phase. Normal phase thin layer chromatography (TLC) plates, with fluorescence indicator at $254 \mathrm{~nm}$, were bought from Sigma-Aldrich (Saint Louis, MO, USA). After exposure to ultraviolet (UV) light (254 and $366 \mathrm{~nm}$ ), the plates were revealed with a sulphuric acid/vanillin based reactive.

The organic solvents, used for CC and TLC, were purchased from Brenntag (Guayaquil, Ecuador) and carefully distilled before using. For GC applications and optical activity, the solvents were analytical grade from Sigma-Aldrich. The specific rotatory power was measured in an automatic polarimeter (Jinan Hanon Instruments Co. Ltd., Jinan, China) model MRC P810. The chiral standards for the enantioselective analysis were provided, as original samples, by one of the authors (C.B.)

All NMR analyses were performed with a Varian $400 \mathrm{MHz}$ spectrometer (Walnut Creek, CA, USA), using deuterated solvent from Sigma-Aldrich. Electron Spray Ionization-Mass Spectrometry (ESI-MS) data were obtained by direct injection in a Bruker Amazon Speed ion trap mass spectrometer (Bruker, Billerica, MA, USA).

Molecular structures and spectroscopic data of compounds 1-5 and 7 are available as Supplementary Material.

\subsection{Plant Material}

The leaves of L. heteromorpha were collected in November 2017, in canton Saruguro, province of Loja (Ecuador), at coordinates $3^{\circ} 39^{\prime} 20.66^{\prime \prime} \mathrm{S}$ and $79^{\circ} 15^{\prime} 20.43^{\prime \prime} \mathrm{W}$ ( $2870 \mathrm{~m}$ above sea level).

The leaves of $L$. radula were collected in June 2015 in the canton Celica, province of Loja (Ecuador), at coordinates $4^{\circ} 4^{\prime} 35.29^{\prime \prime} \mathrm{S}$ and $79^{\circ} 55^{\prime} 39.55^{\prime \prime} \mathrm{W}$ ( $2493 \mathrm{~m}$ above sea level).

L. paniculata leaves were collected also in June 2015 at S. Lucas, in the canton Loja, province of Loja (Ecuador), at coordinates $3^{\circ} 43^{\circ} 33.79^{\prime \prime} \mathrm{S}$ and $79^{\circ} 15^{\prime} 74.29^{\prime \prime} \mathrm{W}$ (2578 $\mathrm{m}$ above sea level). A sample of each species was deposited at the herbarium of the Universidad Técnica Particular de Loja (UTPL), Ecuador, with voucher code HUTPL13744, PPN-LA-034 and PPN-LA-020, respectively. The samples were collected under governmental permission (MAE-DNB-CN-2016-0048) and identified, in the same university (UTPL), by two of the authors (N.C. and V.M.). The fresh leaves of L. heteromorpha were immediately distilled after collection, while L. radula and L. paniculata were dried in the dark at $35^{\circ} \mathrm{C}$ before using. 


\subsection{EO of L. heteromorpha}

\subsubsection{Distillation of the EO}

Four samples of L. heteromorpha fresh leaves (1.50, 1.51, 1.63 and $1.50 \mathrm{~kg}$, respectively) were distilled for $4 \mathrm{~h}$ in four stainless steel Clevenger-type apparatus. The distillates had to be recovered with a solvent because of their very high viscosity. Hence, $100 \mathrm{ml}$ of dichloromethane, spiked with isopropyl hexanoate as internal standard, were added to the aqueous phase. The separated organic phase was then dried over anhydrous sodium sulphate for $30 \mathrm{~min}$ and directly analysed without solvent evaporation. The yield was calculated analytically, as a mean value of the four distillations.

\subsubsection{Qualitative and Semi-quantitative Analysis}

Each sample was analysed by GC(RI), injecting $1 \mu$ l of the previously described EO solution in split mode (40:1), with the injector set at $220^{\circ} \mathrm{C}$. The following oven temperature program was used: $60{ }^{\circ} \mathrm{C}$ for $5 \mathrm{~min}$, a gradient of $3{ }^{\circ} \mathrm{C} / \mathrm{min}$ until $180^{\circ} \mathrm{C}$, then a gradient of $15^{\circ} \mathrm{C} / \mathrm{min}$ up to $250{ }^{\circ} \mathrm{C}$, held for $5 \mathrm{~min}$. The linear retention index (LRI) was calculated for each chromatographic peak, according to Van Den Dool and Kratz [45,46], using a mixture of the homologous series of $n$-alkanes, from $C_{9}$ to $\mathrm{C}_{20}$. The mass spectrometer detector was set in SCAN mode, with 45-350 m/z range for the EO and $40-350 \mathrm{~m} / \mathrm{z}$ for compounds purified after solvent extraction, with a 3 min solvent delay. The carrier gas was maintained at the constant flow of $1 \mathrm{ml} / \mathrm{min}$. The EO components were identified by comparison of the respective EIMS spectra and LRIs to those stored in a reference library [25], with a LRI tolerance of $+/-10$ units.

The semi-quantitative analysis was performed by GC-FID, with the same method and instrumental configuration described for GC(RI). The quantification was achieved by internal calibration, calculating the relative response factor (RRF) of each constituent, referred to the internal standard, on the basis of its combustion enthalpy [47-49]. Isopropyl hexanoate, instead of the methyl octanoate reported in the literature, was chosen as internal standard for this application. This approximation is justified by the principle that the RRF, for isomeric compounds analysed in FID, is about equal to 1 because the combustion enthalpy only depends on the molecular formula.

\subsubsection{Enantioselective GC Analysis}

The enantioselective GC analysis was run with the following oven temperature program: $60{ }^{\circ} \mathrm{C}$ for $5 \mathrm{~min}$, a gradient of $2{ }^{\circ} \mathrm{C} / \mathrm{min}$ up to $220^{\circ} \mathrm{C}$, hold for $2 \mathrm{~min}$. Injection and MS conditions were the same as those reported in the previous paragraph. The elution order of the separated enantiomers was determined by injection of enantiomerically pure standards, available in the laboratory of one of the authors (C.B.).

\subsubsection{Purification of (-)-Ledol and (-)-Caryophyllene oxide}

A preliminary preparative normal phase TLC separation was carried out with $5 \mathrm{mg}$ of the EO distilled from L. heteromorpha. The plate was eluted with a mixture of dichloromethane/methanol 95:5, the analytes detected under UV light $(254$ and $360 \mathrm{~nm}$ ) and a small section of the same plate revealed with vanillin and 5\% sulphuric acid. After scraping the separated bands and eluting them with ethyl acetate, the fractions were analysed by GC-MS, under the same analytical conditions described above (see Supplementary Material for chromatograms).

An amount of $1.4 \mathrm{~g}$ of the EO of L. hereromorpha was submitted to normal phase column chromatography (silica gel). A weight ratio of 1:100 between sample and stationary phase was applied. The elution was achieved isocratically, with a mixture of hexane/dichloromethane 40:60, collecting fractions of $10 \mathrm{~mL}$. The pooled fraction containing sesquiterpenoids (469.2 $\mathrm{mg}$ ) was again fractionated on normal phase $C C$ to achieve a better purification of the major constituent, with a sample/stationary phase ratio of 1:200 by weight and an isocratic elution (hexane/dichloromethane 50:50). Fractions of $15 \mathrm{~mL}$ were collected, from where two compounds were isolated and identified: 
ledol $(459.0 \mathrm{mg})$ and caryophyllene oxide $(8.1 \mathrm{mg})$. The optical activity of both compounds was determined to be levorotatory.

\subsection{Ethyl Acetate Extract Components of L. radula and L. paniculata Leaves}

\subsubsection{Obtainment of Ethyl Acetate Extracts}

Both species, L. radula and L. paniculata, were submitted to the same extraction process. $300 \mathrm{~g}$ of dry leaves were crushed and submitted to room temperature solvent extraction. The plant material was macerated in ethyl acetate for two hours; this operation was repeated three times with fresh solvent, to obtain an almost exhaustive extraction. The resulting solutions were pooled and the solvent removed by vacuum distillation at $30-35{ }^{\circ} \mathrm{C}$, affording $20.2 \mathrm{~g}$ dry extract for L. paniculata and $12.1 \mathrm{~g}$ for L. radula.

\subsubsection{Chlorophyll Removal}

Chlorophylls were removed from the extracts by selective absorption on C18 reversed phase. A vacuum funnel, equipped with a syntherized glass septum, was packed with $\mathrm{C} 18$ reversed phase suspended in pure methanol. The ratio sample/stationary phase was 1:10 by weight. After packing, the organic solvent was completely removed by washing with a great excess of a mixture $\mathrm{CH}_{3} \mathrm{OH} / \mathrm{H}_{2} \mathrm{O}$ 98:2 for L. paniculata and 97:3 for L. radula. The extract $(3.0 \mathrm{~g})$ was then processed by dissolving it in a suitable volume of the same hydro-methanolic mixture used to condition the stationary phase. The whole volume was then eluted under vacuum over the funnel, obtaining a quantitative retention of chlorophylls. Finally, the stationary phase was washed with a large excess of pure methanol, followed by pure ethyl acetate. The resulting solutions were controlled by reversed phase TLC with pure methanol as eluent, to ensure the absence of compounds of interest retained with the chlorophylls.

\subsubsection{Preparative Isolation of Secondary Metabolites from L. radula}

A normal phase CC was carried out with $1.0 \mathrm{~g}$ of chlorophyll-free ethyl acetate extract, over $100 \mathrm{~g}$ of silica gel. The sample was eluted with a mixture of hexane/ethyl acetate, according to an increasing eluotropic strength gradient, from 90:10 to pure ethyl acetate, collecting volumes of about $10 \mathrm{~mL}$. Fractions with similar TLC composition were pooled in 18 different samples and evaporated under vacuum. Further normal phase chromatographic fractionation of these fractions, under similar elution conditions and stationary phase ratio, provided spathulenol $(3,1.5 \mathrm{mg})$, angustanoic acid $\mathrm{E}(4,8.0 \mathrm{mg})$ and 5-hydroxy-4', 7 -dimethoxy flavone (5, $5.1 \mathrm{mg})$.

\subsubsection{Fraction Purification and Secondary Metabolites Isolation from L. paniculata}

A normal phase CC was performed with $1.6 \mathrm{~g}$ of chlorophyll-free ethyl acetate extract, over $160 \mathrm{~g}$ of silica gel. The sample was eluted with a mixture of hexane/ethyl acetate, according to an increasing polarity gradient, from 95:5 to pure ethyl acetate, collecting volumes of about $10 \mathrm{~mL}$. A total of 297 fractions were obtained and then pooled into 18 fractions, according to their qualitative composition in TLC. Purified fraction 7 (3.5 $\mathrm{mg})$ appeared to be a mixture, containing two inseparable major compounds that were identified as ledol (3) and guaiol (6) after GC(RI) analysis.

Fraction $6(20.1 \mathrm{mg})$ was submitted to further isocratic CC fractionation with hexane/ethyl acetate 95:5, giving $15.3 \mathrm{mg}$ of carnosol (7).

\section{Conclusions}

This is the first phytochemical study on the EO obtained from L. heteromorpha, and on the metabolic composition of the ethyl acetate extracts from L. radula and L. paniculata. The $\mathrm{EO}$ of L. heteromorpha was qualitatively and quantitatively characterized and mainly consisted of 27 compounds (including two undetermined), most of them being sesquiterpenoids (63.9\%). A major sesquiterpene alcohol, (-)-ledol (21.2\%), and a minor sesquiterpene epoxide, (-)-caryophyllene oxide (1.0\%), were isolated 
and their structures confirmed by NMR spectroscopy. Other major components were viridiflorene $(27.3 \%),(E, E)-\alpha$-farnesene $(1.4 \%)$, ledol $(21.2 \%)$, spirolepechinene and $(E)$ - $\beta$-caryophyllene $(7.1 \%$ each), allo-aromadendrene (6.1\%), camphor (1.7\%), limonene (1.3\%) and $\beta$-phellandrene (4.6\%).

From the ethyl acetate extract of L. radula spathulenol, angustanoic acid $\mathrm{E}$ and 5-hydroxy-4',7-dimethoxy flavone were purified; L. paniculata afforded ledol, guaiol and (-)-carnosol. All the compounds isolated from the ethyl acetate extracts were described here for the first time in the respective species. Guaiol and ledol, identified in the extract of L. paniculata, are also present, respectively, in L. radula and L. heteromorpha EO.

Supplementary Materials: The following are available online at http:/ /www.mdpi.com/2223-7747/8/1/1/s1, Figure S1: GC-MS comparison of fractions from a preparative TLC analysis of L. heteromorpha EO. The fractions represent compounds that can be separated by normal phase liquid chromatography. Figure S2: ${ }^{1} \mathrm{H}$ NMR (400 $\mathrm{MHz})$ spectrum of compound $\mathbf{1}$ in $\mathrm{CDCl}_{3}$. Figure $\mathrm{S} 3:{ }^{13} \mathrm{C} \mathrm{NMR}(100 \mathrm{MHz})$ spectrum of compound $\mathbf{1}$ in $\mathrm{CDCl}_{3}$. Figure S4: ${ }^{1} \mathrm{H}$ NMR (400 MHz) spectrum of compound 2 in $\mathrm{CDCl}_{3}$. Figure S5: ${ }^{13} \mathrm{C}$ NMR $(100 \mathrm{MHz})$ spectrum of compound 2 in $\mathrm{CDCl}_{3}$. Figure S6: ${ }^{1} \mathrm{H}$ NMR $(400 \mathrm{MHz})$ spectrum of compound 3 in $\mathrm{CDCl}_{3}$. Figure S7: ${ }^{1} \mathrm{H} \mathrm{NMR}$ (400 MHz) spectrum of compound 4 in $\mathrm{CDCl}_{3}$. Figure $\mathrm{S} 8:{ }^{13} \mathrm{C} \mathrm{NMR}(100 \mathrm{MHz})$ spectrum of compound 4 in $\mathrm{CDCl}_{3}$. Figure S9: ${ }^{1} \mathrm{H}$ NMR (400 MHz) spectrum of compound 5 in $\mathrm{CDCl}_{3}$. Figure S10: ${ }^{13} \mathrm{C}$ NMR $(100 \mathrm{MHz})$ spectrum of compound 5 in $\mathrm{CDCl}_{3}$ Figure S11: ${ }^{1} \mathrm{H}$ NMR (400 MHz) spectrum of compound 7 in $\mathrm{CDCl}_{3}$. Figure S12: ${ }^{13} \mathrm{C}$ NMR (100 MHz) spectrum of compound 7 in $\mathrm{CDCl}_{3}$. Table S1: ${ }^{1} \mathrm{H}$ NMR spectroscopic data for compounds 1-5 and 7 (400 MHz, $\delta$ ppm, $\left.\mathrm{CDCl}_{3}\right)$, Table S2: 13C NMR spectroscopic data for compounds $\mathbf{1}, \mathbf{2}, \mathbf{4}, 5$ and $\mathbf{7}(100 \mathrm{MHz}, \delta$ ppm, $\mathrm{CDCl}_{3}$ ).

Author Contributions: Conceptualization, C.B.; Data curation, G.G. and J.R.; Investigation, M.M., W.Q., J.L., L.B., V.M. and N.C.; Methodology, C.B.; Supervision, G.G. and J.R.; Writing - original draft, G.G.; Writing - review \& editing, C.B.

Funding: This research received no external funding.

Acknowledgments: We are grateful to the Universidad Técnica Particular de Loja (UTPL) for supporting this investigation and open access publication.

Conflicts of Interest: The authors declare no conflict of interest.

\section{References}

1. Worldatlas. 17 Most Ecologically Diverse Countries On Earth. Available online: http://www.worldatlas. $\mathrm{com} /$ articles/ecologically-megadiverse-countries-of-the-world.html (accessed on 6 July 2018).

2. Malagón, O.; Ramírez, J.; Andrade, J.M.; Morocho, V.; Armijos, C.; Gilardoni, G. Phytochemistry and Ethnopharmacology of the Ecuadorian Flora. A Review. Nat. Prod. Commun. 2016, 11, 297-314. [PubMed]

3. Finefield, J.M.; Sherman, D.H.; Kreitman, M.; Williams, R.M. Enantiomeric natural products: Occurrence and biogenesis. Angew. Chem. Int. Ed. 2012, 51, 4802-4836. [CrossRef] [PubMed]

4. Brenna, E.; Fuganti, C.; Serra, S. Enantioselective perception of chiral odorants. Tetrahedron Asymmetr. 2003, 14, 1-42. [CrossRef]

5. Liberto, E.; Cagliero, C.; Sgorbini, B.; Bicchi, C.; Sciarrone, D.; d'Acampora-Zellner, B.; Mondello, L.; Rubiolo, P. Enantiomer identification in the flavour and fragrance fields by "interactive" combination of linear retention indices from enantioselective gas chromatography and mass spectrometry. J. Chromatogr. A. 2008, 1195, 117-126. [CrossRef] [PubMed]

6. Ramírez, J.; Gilardoni, G.; Ramón, E.; Tosi, S.; Picco, A.; Bicchi, C.; Vidari, G. Phytochemical Study of the Ecuadorian Species Lepechinia mutica (Benth.) Epling and High Antifungal Activity of Carnosol against Pyricularia oryzae. Pharmaceuticals 2018, 11, 33. [CrossRef] [PubMed]

7. Ramírez, J.; Gilardoni, G.; Jácome, M.; Montesinos, J.; Rodolfi, M.; Guglielminetti, M.L.; Guglielminetti, M.L.; Cagliero, C.; Bicchi, C.; Vidari, G. Chemical Composition, Enantiomeric Analysis, AEDA Sensorial Evaluation and Antifungal Activity of the Essential Oil from the Ecuadorian Plant Lepechinia mutica Benth (Lamiaceae). Chem. Biodivers. 2017, 14. [CrossRef] [PubMed]

8. Parejo, I.; Caprai, E.; Bastida, J.; Viladomat, F.; Jáuregui, O.; Codina, C. Investigation of Lepechinia graveolens for its antioxidant activity and phenolic composition. J. Ethnopharmacol. 2004, 94, 175-184. [CrossRef] [PubMed]

9. Avila, J.G.; Muñoz, J.L.; Martínez, A.; García, A.M.; Martínez, G.; Peñalosa, I. In vitro anti-Vibrio cholerae activity of essential oil from Lepechinia caulescens. Fitoterapia 2005, 76, 104-107. 
10. Martins, F.O.; Esteves, P.F.; Mendes, G.S.; Barbi, N.S.; Menezes, F.S.; Romanos, M.T. Verbascoside isolated from Lepechinia speciosa has inhibitory activity against HSV-1 and HSV-2 in vitro. Nat. Prod. Commun. 2009, 4, 1693-1696. [PubMed]

11. Cicció, J.F.; Soto, V.H.; Poveda, L.J. Essential oil of Lepechinia schiedeana (Lamiaceae) from Costa Rica. Rev. Biol. Trop. 1999, 47, 373-375. [PubMed]

12. Jonathan, L.T.; Che, C.T.; Pezzuto, J.M.; Fong, H.H.S.; Farnsworth, N.R. 7-O-Methylhorminone and Other Cytotoxic Diterpene Quinones From Lepechinla Bullata. J. Nat. Prod. 1989, 52, 571-575. [CrossRef] [PubMed]

13. Missouri Botanical Garden. Available online: http://www.tropicos.org/Name/17602035?tab=acceptednames (accessed on 6 July 2018).

14. Jørgesen, P.M.; León-Yánez, S. Catalogue of the Vascular Plants of Ecuador; Missouri Botanical Garden Press: St. Louis, MO, USA, 1999; p. 521.

15. Missouri Botanical Garden. Available online: http://www.tropicos.org/Name/17602047?tab= acceptednames (accessed on 6 July 2018).

16. Missouri Botanical Garden. Available online: http://www.tropicos.org/Name/17602047?tab=synonyms (accessed on 6 July 2018).

17. Jørgesen, P.M.; León-Yánez, S. Catalogue of the Vascular Plants of Ecuador; Missouri Botanical Garden Press: St. Louis, MO, USA, 1999; p. 522.

18. Morocho, V.; Toro, M.; Cartuche, L.; Guaya, D.; Valarezo, E.; Malagon, O.; Ramirez, J. Chemical Composition and Antimicrobial Activity of Essential Oil of Lepechinia radula Benth Epling. Rec. Nat. Prod. 2017, 11, 57-62.

19. Missouri Botanical Garden. Available online: http://www.tropicos.org/Name/17607770?tab=synonyms (accessed on 6 July 2018).

20. Missouri Botanical Garden. Available online: http:/ / www.tropicos.org/Name/17607770?tab=acceptednames (accessed on 6 July 2018).

21. Valarezo, E.; Castillo, A.; Guaya, D.; Morocho, V.; Malagón, O. Chemical composition of essential oils of two species of Lamiaceae family: Scutellaria volubilis and Lepechinia paniculata from Loja, Ecuador. J. Essent. Oil Res. 2012, 24, 31-37. [CrossRef]

22. de la Torre, L.; Navarrete, H.; Muriel, M.P.; Macía, M.J.; Balslev, H. (Eds.) Enciclopedia de las Plantas Útiles del Ecuador, 1st ed.; Herbario QCA de la Escuela de Ciencias Biológicas de la Pontificia Universidad Católica del Ecuador: Quito, Ecuador; Herbario AAU del Departamento de Ciencias Biológicas de la Universidad de Aarhus: Aarhus, Denmark, 2008; ISBN 978-9978-77-135-8.

23. Rios, M.; Koziol, M.J.; Pedersen, H.B.; Granda, G. (Eds.) Useful Plants of Ecuador: Applications, Challenges, and Perspectives, 1st ed.; Herbario QCA, Pontificia Universidad Católica del Ecuador, and Herbario AAU, Universidad de Aarhus: Quito, Ecuador, 2007; ISBN 978-9978-22-684-1.

24. NIST Chemistry WebBook. Available online: https://webbook.nist.gov/cgi/cbook.cgi?ID=C1139306\& Mask=2000\#Gas-Chrom (accessed on 9 July 2018).

25. Cao, S.G.; Sim, K.Y.; Goh, S.H. (-)-Ledol from Calophyllum teysmanii: Structure and stereochemistry. Nat. Prod. Lett. 2000, 14, 447-452. [CrossRef]

26. Costa, E.V.; De Assis Marques, F.; Pinheiro, M.L.B.; Braga, R.M.; Delarmelina, C.; Duarte, M.C.T.; Ruiz, A.L.; De Carvalho, J.E.; Maia, B. Chemical constituents isolated from the bark of Guatteria blepharophylla (Annonaceae) and their antiproliferative and antimicrobial activities. J. Braz. Chem. Soc. 2011, 22, 1111-1117. [CrossRef]

27. Adams, R.P. Identification of Essential Oil Components by Gas Chromatography/Mass Spectrometry, 4th ed.; Allured Publishing Corporation: Carol Stream, IL, USA, 2007; ISBN 10-1932633219.

28. Ragasa, C.Y.; Ganzon, J.; Hofilena, J.; Tamboong, B.; Rideout, J.A. A New Furanoid Diterpene from Caesaipinia puicherrima. Chem. Pharm. Bull. 2003, 51, 1208-1210. [CrossRef]

29. Sy, L.-K.; Geoffrey, D.B. Abietane Diterpenes from Illicium angustisepalum. J. Nat. Prod. 1998, 3864, 907-912. [CrossRef]

30. Sutthanut, K.; Sripanidkulchai, B.; Yenjai, C.; Jay, M. Simultaneous identification and quantitation of 11 flavonoid constituents in Kaempferia parviflora by gas chromatography. J. Chromatogr. A 2007, 1143, 227-233. [CrossRef]

31. Momozane, T.; Kawamura, T.; Itoh, Y.; Sanosaka, M.; Sasaki, T; Kanzaki, R.; Ose, N.; Funaki, S.; Shintani, Y.; Minami, M.; et al. Carnosol suppresses IL-6 production in mouse lungs injured by ischemia-reperfusion operation and in RAW264.7 macrophages treated with lipopolysaccharide. Biochem. Cell Biol. 2011, 9, 1-24. 
32. Vlavcheski, F.; Baron, D.; Vlachogiannis, I.A.; Macpherson, R.E.K.; Tsiani, E. Carnosol increases skeletal muscle cell glucose uptake via ampk-dependent glut4 glucose transporter translocation. Int. J. Mol. Sci. 2018, 19, 3-6. [CrossRef]

33. Tong, L.; Wu, S. The Mechanisms of Carnosol in Chemoprevention of Ultraviolet B-Light-Induced Non-Melanoma Skin Cancer Formation. Sci. Rep. 2018, 8, 3574. [CrossRef] [PubMed]

34. Giacomelli, C.; Daniele, S.; Natali, L.; Iofrida, C.; Flamini, G.; Braca, A.; Trincavelli, M.L.; Martini, C. Carnosol controls the human glioblastoma stemness features through the epithelial-mesenchymal transition modulation and the induction of cancer stem cell apoptosis. Sci. Rep. 2017, 7, 1-17. [CrossRef]

35. Zhao, H.; Wang, Z.; Tang, F.; Zhao, Y.; Feng, D.; Li, Y.; Hu, Y.; Wang, C.; Zhou, J.; Tian, X.; et al. Carnosol-mediated Sirtuin 1 activation inhibits Enhancer of Zeste Homolog 2 to attenuate liver fibrosis. Pharmacol. Res. 2018, 128, 327-337. [CrossRef]

36. Andrade, J.M.; Faustino, C.; Garcia, C.; Ladeiras, D.; Reis, C.P.; Rijo, P. Rosmarinus officinalis L.: An update review of its phytochemistry and biological activity. Future Sci. OA 2018, 4. [CrossRef] [PubMed]

37. Ramírez, J.; Suárez, A.I.; Bec, N.; Armijos, C.; Gilardoni, G.; Larroque, C.; Vidari, G. Carnosol from Lepechinia mutica (Benth.) Epling and Tiliroside from Vallea stipularis L.f.: Two promising inhibitors of BuChE. Rev. Bras. Farmacogn. 2018, in press.

38. Toyota, M.; Koyama, H.; Mizutani, M.; Asakawa, Y. (-)-ent-spathulenol isolated from liverworts is an artefact. Phytochemistry 1996, 41, 1347-1350. [CrossRef]

39. Esteves, P.F.; Kuster, R.M.; Barbi, N.D.S.; Menezes, F.D.S. Chemical composition and cytotoxic activity of Lepechinia speciosa (St. Hill) Epling. Lat. Am. J. Pharmacy 2010, 29, 38-44.

40. Delgado, G.; Hernández, J.; Chávez, M.I.; Álvarez, L.; Gonzaga, V.; Martínez, E. Di- and triterpenpoid acids from Lepechinia caulescens. Phytochemistry 1994, 37, 1119-1121. [CrossRef]

41. Delgado, G.; Sánchez, E.; Hernández, J.; Chávez, M.I.; Álvarez, L.; Martínez, E. Abietanoid acid from Lepechinia caulescens. Phytochemistry 1992, 31, 3159-3161. [CrossRef]

42. Bruno, M.; Savona, G.; Piozzi, F.; De la Torre, M.; Rodríguez, B.; Marlier, M. Abietane diterpenoids from Lepechinia meyeni and Lepechinia hastata. Phytochemistry 1991, 30, 2339-2343. [CrossRef]

43. Areche, C.; Schmeda-Hirschmann, G.; Theoduloz, C.; Rodríguez, J.A. Gastroprotective effect and cytotoxicity of abietane diterpenes from the Chilean Lamiaceae Sphacele chamaedryoides (Balbis) Briq. J. Pharmacy Pharmacol. 2009, 61, 1689-1697. [CrossRef]

44. Eggers, M.D.; Sinnwell, V.; Stahl-Biskup, E. (-)-Spirolepechinene, a spirosesquiterpene from Lepechinia bullata (Lamiaceae). Phytochemistry 1999, 51, 987-990. [CrossRef]

45. Van Den Dool, H.; Dec. Kratz, P. A generalization of the retention index system including linear temperature programmed gas-Liquid partition chromatography. J. Chromatogr. A 1963, 11, 463-471. [CrossRef]

46. D'Acampora-Zellner, B.; Bicchi, C.; Dugo, P.; Rubiolo, P.; Dugo, G.; Mondello, L. Linear retention indices in gas chromatographic analysis: A review. Flavour Fragr. J. 2008, 23, 297-314. [CrossRef]

47. Bicchi, C.; Liberto, E.; Matteodo, M.; Sgorbini, B.; Mondello, L.; d'Acampora-Zellner, B.; Costa, R.; Rubiolo, P. Quantitative analysis of essential oils: A complex task. Flavour Fragr. J. 2008, 23, 382-391. [CrossRef]

48. De Saint Laumer, J.I.; Cicchetti, E.; Merle, P.; Egger, J.; Chaintreau, A. Quantification in Gas Chromatography: Prediction of Flame Ionization Detector Response Factors from Combustion Enthalpies and Molecular Structures. Anal. Chem. 2010, 82, 6457-6462. [CrossRef]

49. Tissot, E.; Rochat, S.; Debonneville, C.; Chaintreau, A. Rapid GC-FID quantification technique without authentic samples using predicted response factors. Flavour Fragr. J. 2012, 27, 290-296. [CrossRef]

(C) 2018 by the authors. Licensee MDPI, Basel, Switzerland. This article is an open access article distributed under the terms and conditions of the Creative Commons Attribution (CC BY) license (http://creativecommons.org/licenses/by/4.0/). 